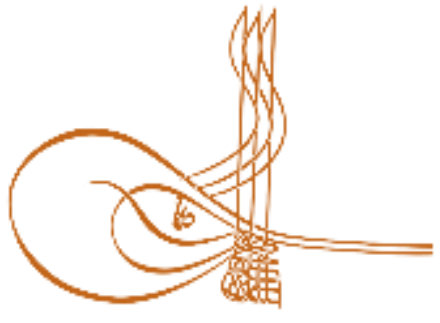

www.turkishstudies.net/social
Turkish Studies - Social Sciences

eISSN: $2667-5617$

Research Article / Araşttrma Makalesi

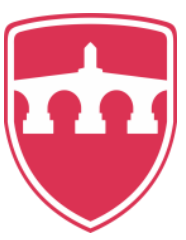

INTERNATIONAL

BALKAN

UNIVERSITY

Sponsored by IBU

\title{
Kırsal Turizm ve Türlerine Yönelik Hazırlanan Lisansüstü Tezlerin Bibliyometrik Analizi
}

\author{
Bibliyometric Analysis of Graduate Theses for Rural Tourism
}

\author{
Aslı Albayrak* - Demet Tüzünkan*
}

\begin{abstract}
After 2000's, rural tourism which is located under the touristic product diversification and has great interest not only in Turkey but also in the worldwide, has become an activity by more tourists every year. Since the motivations that direct tourists to rural tourism are to experience rural areas, many different types of tourism such as plateau tourism, agro tourism, botanical tourism and cave tourism are also included in the scope of rural tourism. Therefore, it is seen that there are many studies in the field regarding the types of tourism evaluated within the scope of rural tourism, and even congresses and symposiums related to rural tourism have been held. It is thought that the studies done and to be done about rural tourism and its types, which contribute significantly to the increase in tourism demand, will have positive effects on both to the development and sustainability of tourism and to the tourism literature. The main purpose of this study is to determine the general characteristics of the graduate thesis studies about rural tourism and to give an idea about the development of rural tourism to the tourism plans and politicians as well as to the researchers who will study in this field. Documentary scanning method was used in the study. In this context, the scanning was carried out in the thesis search menu of the National Thesis Center Database about the concepts of rural tourism, agricultural tourism, agro-tourism, botanical tourism, plateau tourism, cave tourism, bird watching tourism and farm tourism. The parameters in the previous studies were used while in the examination of the related theses. Parameters in the previous studies were used to analyze the theses related. As a result of the study, various suggestions were made to the sector employees and researchers in order to realize rural tourism and other types of tourism more effectively.
\end{abstract}

Structured Abstract: Rural tourism is a type of tourism where visitors experience nature-based activities such as agriculture, rural life style, fisheries, and it has features such as doing it in places where agriculture and animal husbandry are low and the traditional social structure and the preservation of life style are important. Rural tourism does not only cover agricultural and farm tourism activities, but in a broad sense it is defined as

\footnotetext{
* Doç. Dr., İstanbul Gelişim Üniversitesi, Güzel Sanatlar Fakültesi, Gastronomi ve Mutfak Sanatları Bölümü Assoc. Prof. Dr. İstanbul Gelisim University, Faculty of Fine Arts, Department of Gastronomy and Culinary Arts ORCID 0000-0003-1002-2476 aalbayrak@gelisim.edu.tr

* Dr. Öğr. Üyesi, İstanbul Kent Üniversitesi, Sanat ve Tasarım Fakültesi, Gastronomi ve Mutfak Sanatları Bölümü Asst. Prof. Dr. İstanbul Kent University, Faculty of Arts and Design, Department of Gastronomy and Culinary Arts ORCID 0000-0003-0440-294X

demet.tuzunkan@kent.edu.tr

Cite as/ Atıf: Albayrak, A., Tuzunkan, D. (2020). Kırsal turizm ve türlerine yönelik hazırlanan lisansüstü tezlerin bibliyometrik analizi, Turkish Studies - Social, 15(1), 845-859. https://dx.doi.org/10.29228/TurkishStudies.40613

Received/Geliş: 17 January/Ocak 2020

Accepted/Kabul: 25 February/Şubat 2020

Copyright $(C)$ INTAC LTD, Turkey
} 
activities to benefit from rural-specific production and tranquility environment, natural resources, recreational and informational activities in interaction with socio-cultural values created by the rural community and taken over from the past. Rural tourism may differ by region. While one region is suitable for plateau tourism, another region may be suitable for mountain or agricultural tourism. Turkey has outstanding features compared to other countries in terms of natural values. Although rural tourism includes plateau tourism, hunting tourism, cave tourism, ecotourism and nature sports tourism, each of them includes different activities in itself. Rural tourism, which has a complementary structure to agriculture, is especially important because of its additional income source for rural people.

In this study, a bibliometric analysis was carried out in the field of rural tourism in line with the Master's and Doctorate thesis studies. In this context, it has been possible to reach conclusions such as the types, years, distribution of the thesis about the types of tourism, the language of the thesis, and the field of study. The main purpose of this study is to determine the general characteristics of postgraduate thesis studies prepared for rural tourism and other tourism types that are included in the scope of rural tourism. Within the scope of the study, "Rural Tourism" and "Ecotourism, Plateau Tourism, Nature Tourism, Nature Based Tourism, Bird Watching Tourism, Rural Recreation Tourism, Farm Tourism, Mountain Tourism, Hunting Tourism Agriculture (Agro) Tourism" which are included in the scope of rural tourism were taken.

The aim of the study is to contribute to the development of Rural Tourism, to inform relevant institutions, organizations and individuals and to guide other researchers through post-graduate researches related to other tourism types within the scope of Rural Tourism. It is thought that the general framework regarding the rural tourism and its types with the statistical data of the findings to be obtained as a result of the research is important in terms of eliminating the deficiency in the literature.

When the national literature is evaluated, there are studies examining theses in the field of tourism by years, universities, subjects, institutes and fields. However, there are also studies prepared by Rural Tourism and Ecotourism in the literature. However, no study has been encountered in our country where other tourism types included in the scope of Rural Tourism are evaluated together. Therefore, it is thought that the study of Rural Tourism as a whole from a wider frame will contribute to the development of the literature on Rural Tourism. On the other hand, considering that graduate thesis contribute to the development of a discipline, the study will contribute to creating a discipline related to Rural Tourism and its scope.

Documentary scanning method was used to collect the data needed for the study, as well as to make definitions, explanations and evaluations on the subject. In the thesis search menu on National Thesis Center Database, within the scope of Rural Tourism, Ecotourism, Plateau Tourism, Nature Based Tourism, Bird Watching Tourism, Rural Recreation Tourism, Farm Tourism, Mountain Tourism, Hunting Tourism, Agro Tourism, Cave Tourism and Botanical Tourism have been determined. Since no study on cave tourism was found in the examination made in the National Thesis Center Database, the study continued with 11 types of tourism. 144 graduate thesis have been reached. The related thesis were evaluated by the parameters which were used by Şahin and Acun in 2015. The bibliometric method was evaluated in terms of percentage and frequency values of the related parameters.

When the findings are evaluated, it is noteworthy that the majority of master's and doctoral thesis are held in the field of eco tourism. While the quantitative research methods were used in the Master's Thesis, the qualitative research methods were mostly used in the Doctoral thesis. It was determined that survey methods were mostly used as the data collection technique in both Master and Doctorate thesis. Especially when Turkey's rich natural tissue is considered the lack of studies in botany and birding subject is considered as a deficiency. In the framework of rural tourism, there are only 30 doctoral thesis studied in Turkey is one of the remarkable results. Therefore, it is recommended to focus on the studies that will encourage regional development and the development of rural tourism types in Turkey.

According to the data obtained as a result of the study, thesis are mostly written in big city universities. It is important to reveal the rural tourism potential of the regions in the small cities, where constitute an important resource and potential for rural tourism.

Keywords: Dicipline, Bibliometric analysis, Rural tourism, Rural tourism types, Thesis 
Öz: Turistik ürün çeşitlendirmesi içerisinde yer alan ve özellikle 2000'li yıllardan sonra sadece Türkiye'de değil dünyada da büyük ilgi görmeye başlayan kırsal turizm her geçen gün daha fazla turistin katıldığı bir turizm türü haline gelmiştir. Turistleri kırsal turizme yönelten motivasyonlar kırsal alanları deneyimlemek olduğundan kırsal turizm kapsamına yayla turizmi, agro turizm, botanik turizmi, mağara turizmi gibi pek çok farklı turizm türü de girmektedir. Dolayısıyla kırsal turizm kapsamında değerlendirilen turizm türlerine ilişkin alan yazında pek çok çalışma olduğu hatta kırsal turizmle ilgili kongre ve sempozyumların da yapıldığı görülmektedir. Turizm talebinin artmasına önemli katkı sağlayan kırsal turizm ve türleri ile ilgili yapılan ve yapılacak çalışmaların hem turizmin gelişimi ve sürdürülebilirliğine hem de literatüre katkı sağlayacağı düşünülmektedir. $\mathrm{Bu}$ çalışmanın temel amacı kırsal turizm ile ilgili hazırlanan lisansüstü tez çalışmalarının genel özelliklerini tespit etmek ve hem turizm plan ve politikacılarına kırsal turizmin gelişimi açısından hem de bu alanda çalışacak araştırmacılara literatür açısından fikir vermektir. Çalışmada belgesel tarama yönteminden yararlanılmıştır. Bu kapsamda Ulusal Tez Merkezi Veri Tabanında yer alan tez arama menüsünde kırsal turizm, tarım turizmi, agro-turizm, botanik turizmi, yayla turizmi, mağara turizmi, kuş gözlemciliği turizmi ve çiftlik turizmi kavramları üzerinden tarama gerçekleştirilmiştir. İlgili olan tezlerin incelenmesinde daha önceden yapılan çalışmalarda yer alan parametrelerden yararlanılmıştır. Çalışma sonucunda kırsal turizm ve kapsamında yer alan diğer turizm türlerinin daha etkin olarak gerçekleştirilebilmesi için sektör çalışanlarına ve araştırmacılara çeşitli önerilerde bulunulmuştur.

Anahtar Kelimeler: Bilim dalı, Bibliyometrik analiz, Kırsal turizm, Kırsal turizm türleri, Turizm, Tez

\section{Giriş}

Birleşmiş Milletler Dünya Turizm Örgütü’ne göre kırsal turizm, ziyaretçilerin tarım, kırsal yaşam tarzı, balıkçılık gibi doğa temelli aktiviteleri deneyimlediği bir turizm çeşidi olup, nüfus yoğunluğunun düşük olduğu, tarım ve hayvancilığın bulunduğu yerlerde yapılması ve geleneksel sosyal yapı ile yaşam tarzının korunmasına önem verilmesi gibi özelliklere sahiptir (UNWTO). Kırsal turizm, sadece tarım ve çiftlik turizmi faaliyetlerini kapsamamakta olup, geniş anlamda, "kırsal alanda yaşayan toplum tarafindan oluşturulan ve geçmişten devraldığı sosyo-kültürel değerlerle etkileşim halinde, kırsal alana özgü üretim ve huzur ortamından, doğal kaynaklardan, dinlenme ve bilgilenme amaçlı yararlanma faaliyetleri" (Özçatalbaş, 2006:3) olarak tanımlanmaktadır. İstihdam yaratıcı, kalkınmaya ve altyapıya katkı sağlayıcı, kültüre ve doğal çevreye olumlu etkileri bulunan kırsal turizm, çok yönlü ve karmaşık bir yapıya sahip olup, çiftlik turizmi, yeşil turizm, tarım turizmi veya yayla turizmi gibi farklı isimlerle de anılmaktadır (Uçar, vd., $2012: 76-77)$.

Kırsal turizm, bölgelere göre farkl1lıklar içerebilmektedir. Bir bölge, yayla turizmi yapılmasına elverişli iken başka bir bölge dağ ya da tarım turizmi yapılmasına elverişli olabilmektedir. Türkiye, tarih, kültür, doğal değerler açısından diğer lkelere göre öne çıkan özelliklere sahiptir. Coğrafi yapısından ötürü Türkiye, dağ ve orman köyleri, yaylalar, ova köyleri, vadiler, şelaleler, balıkçılık, rafting, yamaç paraşütü gibi çeşitli turistik ürünlere sahip olup aynı zamanda ülkenin farklı bölgelerindeki Türk kültürünün yansıtıldığı yöresel el sanatları, Anadolu folkloru, geleneksel köy düğünleri, geleneksel sporlar da kırsal turizmi kültürel yönden besleyip bir mozaik oluşturmaktadırlar (Çeken, vd., 2007 :9).

Kırsal turizm içinde yayla turizmini, av turizmini, mağara turizmini, ekoturizmi, doğa sporları turizmini de içerse de her biri kendi içinde farklı aktiviteleri kapsamaktadır. Kuş gözlemciliği, kırsal temalı animasyon ve rekreasyon faaliyetleri bu aktivitelerin içinde yer almakla birlikte kırsal turizme katılanların doğanın içinde, çiftliklerde, dağlarda ya da köylerde konaklama yaptıkları görülmektedir (Yazıcı, vd., 2017: 133). Tarımı tamamlayıcı bir yapı gösteren kırsal turizm özellikle kırsal alanda yaşayan insanlar için ek gelir kaynăg 1 yaratma özelliğinden ötürü oldukça önemlidir. Türkiye'de kırsal turizm, son yıllarda yerli ve yabancı kaynaklarla desteklenen projeler sayesinde büyük önem kazanmıştır (Şerefoğlu, 2009: 81). T.C. Kültür ve Turizm Bakanlığı da, kırsal turizm kapsamı içinde değerlendirilen turizm çeşitleri arasında yer alan yayla turizmi, mağara 
turizmi, av turizmi, hava sporları, dağcılık, akarsu-rafting turizmi ve kuş gözlemciliği konularında Türkiye'nin zenginliklerini internet sitesinde paylaşmaktadır (T.C. Kültür ve Turizm Bakanlığı).

$\mathrm{Bu}$ çalışmada kırsal turizm alanında şimdiye kadar yapılan Yüksek lisans ve Doktora tez çalışmaları doğrultusunda bir bibliyometrik analiz çalışması gerçekleştirilmiştir. Bu bağlamda, kırsal turizm ve kapsamı altında yer alan turizm çeşitleri hakkında yazılan tezlerin türü, yılları, üniversitelere göre dağılımı, hangi dilde yazıldığı, hangi anabilim dalının altında çalışıldığı gibi sonuçlara ulaşmak mümkün olmuştur.

\section{Araştırmanın Amacı}

$\mathrm{Bu}$ çalışmanın temel amacı kırsal turizm ve kırsal turizm kapsamına giren diğer turizm türleri ile ilgili hazırlanan lisansüstü tez çalışmalarının genel özelliklerini tespit etmek ve hem turizm plan ve politikacılarına kırsal turizmin gelişimi açısından hem de bu alanda çalışacak araştırmacılara alan yazın açısından fikir vermektir. Çalışma kapsamında 'Kırsal Turizm' ve kırsal turizm kapsamı içerisinde yer alan 'Ekoturizm, Yayla Turizmi, Doğa Turizmi, Doğa Temelli Turizm, Kuş Gözlemciliği Turizmi, Kırsal Rekreasyon Turizmi, Çiftlik Turizmi, Dağ Turizmi, Av turizmi Tarım (Agro) Turizmi' alınmıştır. Çalışmanın temel amacına bağlı olarak belirlenen turizm türleriyle ilgili aşağıdaki sorulara cevap aranmaya çalışılmıştır:

1. Kırsal turizm ve kırsal turizm kapsamına giren diğer turizm türlerine yönelik hazırlanan tezlerin yüksek lisans ve doktora tez dağılımı nasıldır?

2. Tezlerin yıllara göre dağılımı nasıldır?

3. Tezlerin dil açısından dağılımı ne şekildedir?

4. İlgili tezler hangi üniversiteler bünyesinde hazırlanmıştır?

5. Kırsal turizm ve kırsal turizm kapsamına giren diğer turizm türlerine yönelik hazırlanan tezler hangi enstitüler bünyesinde hazırlanmıştır?

6. Tezlerin anabilim dallarına göre dağılımı ne şekildedir?

7. Tezlerdeki danışmanların unvanlarına göre dağılımı ne şekildedir?

8. Tezlerin sayfa sayısı kaçtır?

9. İlgili tezlerde yerli ve yabancı kaynakça kullanımı ne durumdadır?

10. Tezlerde hangi anahtar kelimeler kullanılmıştır?

11. Alan araştırması içeren tezlerde yöntem içeriği ne şekildedir?

Çalışmanın temasını oluşturan "Kırsal Turizm ve Kırsal Turizm kapsamında yer alan diğer turizm türleri ile ilgili lisansüstü araştırmalar aracılığ ile Kırsal Turizm'in gelişimine katkı sağlamak, ilgili kurum, kuruluş ve şahısları bilgilendirmek ve diğer araştırmacılara yol göstermek hedeflenmektedir. Araştırma sonucunda elde edilecek bulguların kırsal turizmi ve türleriyle ilgili genel çerçevenin istatistiki veriler ile ortaya konması literatürdeki eksikliğin giderilmesi açısından önemli olduğu düşünülmektedir.

\section{Yöntem}

Ulusal alan yazın değerlendirildiğinde turizm alanında yapılan tezleri, yıllara, üniversitelere, konularına, enstitülerine ve alanlarına göre inceleyen (Cevizkaya, İlsay ve Avcıkurt, 2014; Güçlü, 2014; Şahin ve Acun, 201; Tayfun vd., 2016; Tekin, 2016; Sünnetçioğlu vd., 2017; Ayaz ve Türkmen, 2018) çalışmalar bulunmaktadır. Bununla birlikte alan yazında Kırsal Turizm (Bozok vd., 2017) ve Ekoturizm (Gökkaya vd., 2017) tarafından hazırlanan çalışmalar da bulunmaktadır. Fakat ülkemizde Kırsal Turizm kapsamına giren diğer turizm türlerinin bir arada değerlendirildiği bir 
çalışmaya karşılaşılmamıştır. Dolayısıyla Kırsal Turizmin daha geniş bir çerçeveden bütünü teşkil edecek şekilde irdelenmesinin Kırsal Turizme ilişkin alan yazının gelişmesine katkı sağlayacağı düşünülmüştür. Diğer taraftan lisansüstü tezlerin bir disiplinin gelişmesine önemli katkılar sağladığ1 düşünüldügünde (Kervankıran ve Şardağ, 2018: 155) çalışmanın Kırsal Turizm ve kapsamına ilişkin bir disiplin oluşturmaya katk1 sağlayacağı düşünülmüştür.

Bu çalışmanın amacı, Türkiye'deki Kırsal Turizm ve Kırsal Turizm kapsamına giren diğer turizm türleriyle ilgili lisansüstü tezlerin çeşitli parametreler çerçevesinde bibliyometrik analizinin gerçekleştirilmesidir. Çalışma kapsamına alınacak olan turizm türlerinin belirlenmesinde Albayrak (2013: 132-167) tarafından yapılan çalışmada belirtilen Kırsal turizm ve türlerinden yararlanılmıştır. Çalışma için ihtiyaç duyulan verilerin toplanması, ayrıca konu ile ilgili tanım, açıklama ve değerlendirilmelerin yapılmasında belgesel tarama yöntemi kullanılmıştır. Mevcut kayıt ve belgelerin sistemli bir biçimde incelenmesi yolu ile verilerin toplandığı belgesel tarama yöntemi, yazılı belgeler aracılığı ile kaynakları bulma, okuma, not alma ve değerlendirme sürecidir (Karasar, 1991: 183).

Çalışma kapsamında Ulusal Tez Merkezi Veri Tabanında yer alan tez arama menüsünde Kırsal Turizm ve kırsal turizm kapsamı içerisinde yer alan Ekoturizm, Yayla Turizmi, Doğa Temelli Turizm, Kuş Gözlemciliği Turizmi, Kırsal Rekreasyon Turizmi, Çiftlik Turizmi, Dağ Turizmi, Av turizmi, Tarım (Agro) Turizmi, Mağara Turizmi ve Botanik Turizmi olmak üzere 12 ana başlık belirlenmiştir. Ulusal Tez Merkezi Veri Tabanında yapılan incelemede Mağara turizmi ile ilgili yapılan bir çalışmaya rastlanmadığından çalışmaya 11 turizm türüyle devam edilmiştir. Bu bağlamda toplam 144 lisansüstü teze ulaşılmıştır. İlgili tezler Şahin ve Acun (2015) tarafından yapılan çalışmada kullandıkları parametreler açısından değerlendirilmiş, araştırma sonucunda elde edilen verilerin analizinde bibliyometrik yöntem kullanılarak ilgili parametrelerin yüzde ve frekans değerleri açısından değerlendirilmiştir.

\section{Bulgular ve Tartışma}

Bu bölümde Kırsal Turizm ve kapsamı içerisinde yer alan turizm türleriyle ilgili lisansüstü çalışmalardan elde edilen veriler ışığında lisansüstü tezlerin türü, tezlerin yapıldı̆̆ı yıllar, tezlerin üniversiteleri, enstitüleri, anabilim dalları, danışmanların unvanları, sayfa ve kaynakça sayıları, araştırma alanı ve çalışma grubu ile ilgili bilgiler tablolaştırılmıştır.

Tablo 1: Çalışma Kapsamına Alınan Lisansüstü Çalışmaların Turizm Türlerine Göre Dağılımı

\begin{tabular}{lcccccc}
\hline \multirow{2}{*}{ TURİM TÜRÜ } & \multicolumn{2}{c}{ Yüksek Lisans } & \multicolumn{2}{c}{ Doktora } & \multicolumn{2}{c}{ TOPLAM } \\
\cline { 2 - 7 } & $\mathbf{f}$ & $\mathbf{\%}$ & $\mathbf{f}$ & $\mathbf{\%}$ & $\mathbf{f}$ & \% \\
\hline Ekoturizm & 59 & 51.8 & 12 & 40.0 & 71 & 49.3 \\
\hline Kırsal Turizm & 24 & 21.5 & 7 & 23.3 & 31 & 21.5 \\
\hline Tarım Turizmi & 14 & 12.2 & 5 & 16.7 & 19 & 13.2 \\
\hline Yayla Turizmi & 9 & 7.8 & 1 & 3.3 & 10 & 6.9 \\
\hline Av Turizmi & 4 & 3.5 & 0 & 0.0 & 4 & 2.8 \\
\hline Kursal Rekreasyon Turizmi & 0 & 0.0 & 2 & 6.7 & 2 & 1.4 \\
\hline Çiftlik Turizmi & 0 & 0.0 & 2 & 6.7 & 2 & 1.4 \\
\hline Doğa Temelli Turizm & 1 & 0.8 & 1 & 3.3 & 2 & 1.4 \\
\hline Dă̆ Turizmi & 1 & 0.8 & 0 & 0.0 & 1 & 0.7 \\
\hline Botanik Turizmi & 1 & 0.8 & 0 & 0.0 & 1 & 0.7 \\
\hline Kuş Gözlemciliği Turizmi & 1 & 0.8 & 0 & 0.0 & 1 & 0.7 \\
\hline TOPLAM & $\mathbf{1 1 4}$ & $\mathbf{1 0 0 . 0}$ & $\mathbf{3 0}$ & $\mathbf{1 0 0 . 0}$ & $\mathbf{1 4 4}$ & $\mathbf{1 0 0 . 0}$ \\
\hline
\end{tabular}


Tablo 1 'de çalışma kapsamına alınan lisansüstü çalışmaların turizm türlerine göre dağılımı yer almaktadır. Tablo 1 değerlendirildiğinde Kırsal Turizm kapsamında yer alan turizm türlerinden yarısından fazlası (\%49.3) Ekoturizm ile ilgili olduğu görülmektedir. Kırsal turizm kapsamında çalışılan diğer turizm türleri ise sırasıyla Kırsal Turizm (\%21.5), Tarım Turizmi (\%13.2), Yayla Turizmi (\%6.9), Av Turizmi (\%2.8), eşit oranlarla Kırsal Rekreasyon Turizmi ile Çiftlik Turizmi (\%1.4) ve yine eşit oranlarla Doğa Temelli Turizm, Dağ Turizmi, Botanik Turizmi ve Kuş Gözlemciliği Turizmi (\%0.7) takip etmektedir.

Kırsal turizm kapsamında yapılan lisansüstü çalışmalar dereceleri açısından değerlendirildiğinde Yüksek Lisans tezlerinin yarıdan fazlasının (\%51.8), Doktora tezlerinin ise üçte birinden fazlasının (\%40.0) Ekoturizm ile ilgili olduğu görülmüştür. Hem Yüksek Lisans hem de Doktora düzeyinde hazırlanan çalışmalarda Ekoturizmi sırasıyla Kırsal Turizm (Yüksek Lisans \%21,5; Doktora \%23.3) ve Tarım Turizmi (Yüksek Lisans \%12.2; Doktora \%16.6) takip etmektedir. Üçüncü en fazla çalışılan konu ise Yüksek Lisans düzeyinde Yayla Turizmi (\%7.8) Doktora düzeyinde ise eşit oranlarla Kırsal Rekreasyon ve Çiftlik Turizmidir (\%6.7).

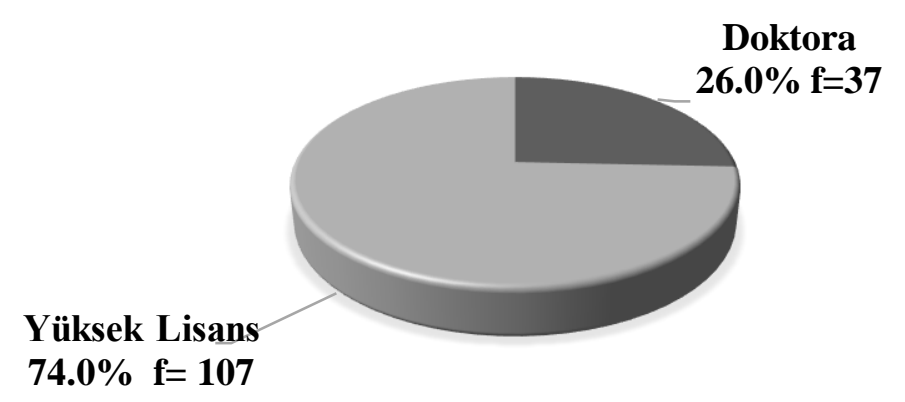

Grafik 1: Kırsal Turizm Kapsamında YÖK Ulusal Tez Merkezi Veri Tabanında Yer Alan Lisansüstü Çalışmaların Türlerine Göre Dağılımı

Kırsal Turizm Kapsamında YÖK Ulusal Tez Merkezi Veri Tabanında Yer Alan Lisansüstü Çalışmaların Türlerine Göre Dağılımı Grafik 1'de yer almaktadır. Buna göre çalışma kapsamında değerlendirilen ve Kırsal Turizm kapsamı içerisinde yer alan turizm türlerine ilişkin yapılmış olan tezlerin \%74.0’ü Yüksek Lisans, \%26.0’1 ise Doktora düzeyindedir.

Tablo 2: Kırsal Turizm Kapsamında Yer Alan Tezlerin Yıllara Göre Dağılımı

\begin{tabular}{lcccccc}
\hline Yll & \multicolumn{1}{c}{ Yüksek Lisans } & \multicolumn{2}{c}{ Doktora } & \multicolumn{2}{c}{ TOPLAM } \\
\hline & $\mathbf{f}$ & $\mathbf{\%}$ & $\mathbf{f}$ & $\mathbf{\%}$ & $\mathbf{f}$ & \% \\
\hline 2010 ve sonrasi & 86 & 75.5 & 18 & 60.0 & 104 & 72.2 \\
\hline $2005-2009$ & 21 & 18.4 & 7 & 23.3 & 28 & 19.4 \\
\hline 2000-2004 & 4 & 3.5 & 3 & 10.0 & 7 & 4.9 \\
\hline 1999 ve öncesi & 3 & 2.6 & 2 & 6.7 & 5 & 3.5 \\
\hline Toplam & $\mathbf{1 1 4}$ & $\mathbf{1 0 0 . 0}$ & $\mathbf{3 0}$ & $\mathbf{1 0 0 . 0}$ & $\mathbf{1 4 4}$ & $\mathbf{1 0 0 . 0}$ \\
\hline
\end{tabular}

Tablo 2'de Kırsal Turizm ve kapsamı içerisinde yer alan turizm türleri ile ilgili lisansüstü tezlerin yıllara göre dağılımı yer almaktadır. Hazırlanan tezlerin yıllara göre dağılımına bakıldığında söz konusu çalışmaları dörtte üçüne yakınının (\%72.2) 2010 yılı sonrasında yapıldığı, \%19.4'ünün 2005-2009 tarihleri arasında, \%4.9'unun 2000-2004 y1lları arasında ve \%3.5'inin 1999 yılı ve öncesinde yapıldığı görülmektedir. Söz konusu tezler çalışıldıkları düzey açısından değerlendirildiğinde de toplam sonuçlarına benzer sonuçlar görülmektedir. Buradan hareketle hem Yüksek Lisans hem de Doktora düzeyinde en fazla çalışmaların 2010 yılı sonrası yapıldığı ve her iki düzeyde de 1999 yılı öncesi yapılan çalışmaların oldukça kısıtlı olduğu görülmektedir. 
Tablo 3: Kırsal Turizm Kapsamında Yer Alan Tezlerin Dillerine Göre Dağılımı

\begin{tabular}{lcccccc}
\hline \multirow{2}{*}{ DİL } & \multicolumn{2}{c}{ Yüksek Lisans } & \multicolumn{2}{c}{ Doktora } & \multicolumn{2}{c}{ TOPLAM } \\
\cline { 2 - 7 } & $\mathbf{f}$ & $\mathbf{\%}$ & $\mathbf{f}$ & $\mathbf{\%}$ & $\mathbf{f}$ & $\mathbf{\%}$ \\
\hline Türkçe & 111 & 97.4 & 30 & 100.0 & 141 & 97.9 \\
\hline İngilizce & 3 & 2.6 & 0 & 0.0 & 3 & 2.1 \\
\hline Toplam & $\mathbf{1 1 4}$ & $\mathbf{1 0 0 . 0}$ & $\mathbf{3 0}$ & $\mathbf{1 0 0 . 0}$ & $\mathbf{1 4 4}$ & $\mathbf{1 0 0 . 0}$ \\
\hline
\end{tabular}

Tablo 3'te Kırsal Turizm ve kapsamında yer alan tezlerin dillerine göre dağ 1 lımı yer almaktadır. Genel bir değerlendirme yapıldığında toplam tezlerin neredeyse tamamı (\%97.9) Türkçe dilinde hazırlanmıştır. Söz konusu çalışmalar düzeylerine göre değerlendirildiğinde Doktora düzeyinde hazırlanan tüm tezlerin Türkçe olduğu, Yüksek Lisans düzeyinde ise hazırlanan çalışmaların sadece \%2.6'sı Türkçe dışında bir dide (İngilizce) hazırlanmıştır. 
Tablo 4: Kırsal Turizm Kapsamında Yer Alan Tezlerin Üniversitelere Göre Dağılımı

\begin{tabular}{|c|c|c|c|c|c|c|}
\hline \multirow[t]{2}{*}{ Üniversite } & \multicolumn{2}{|c|}{ Yüksek Lisans } & \multicolumn{2}{|c|}{ Doktora } & \multicolumn{2}{|c|}{ TOPLAM } \\
\hline & $\mathbf{f}$ & $\%$ & $\mathbf{f}$ & $\%$ & f & $\%$ \\
\hline Adnan Menderes & 2 & 1.7 & 0 & 0.0 & 2 & 1.4 \\
\hline Afyon Kocatepe & 2 & 1.7 & 3 & 10.0 & 5 & 3.5 \\
\hline Akdeniz & 2 & 1.7 & 1 & 3.3 & 3 & 2.1 \\
\hline Ankara & 5 & 4.4 & 6 & 20.0 & 11 & 7.6 \\
\hline Artvin & 1 & 0.8 & 0 & 0.0 & 1 & 0.7 \\
\hline Atatürk & 4 & 3.5 & 1 & 3.3 & 5 & 3.5 \\
\hline Atılım & 1 & 0.8 & 0 & 0.0 & 1 & 0.7 \\
\hline Balıkesir & 3 & 2.6 & 2 & 6.7 & 5 & 3.5 \\
\hline Bilecik Şeyh Edibali & 1 & 0.8 & 0 & 0.0 & 1 & 0.7 \\
\hline Bilgi & 1 & 0.8 & 0 & 0.0 & 1 & 0.7 \\
\hline Bozok & 1 & 0.8 & 0 & 0.0 & 1 & 0.7 \\
\hline Cumhuriyet & 1 & 0.8 & 0 & 0.0 & 1 & 0.7 \\
\hline Çanakkale & 7 & 6.1 & 0 & 0.0 & 7 & 4.9 \\
\hline Çukurova & 0 & 0.8 & 1 & 3.3 & 1 & 0.7 \\
\hline Dokuz Eylül & 6 & 5.3 & 2 & 6.7 & 8 & 5.5 \\
\hline Düzce & 3 & 2.6 & 0 & 0.0 & 3 & 2.1 \\
\hline Ege & 1 & 0.8 & 0 & 0.0 & 1 & 0.7 \\
\hline Eskişehir Anadolu & 1 & 0.8 & 0 & 0.0 & 1 & 0.7 \\
\hline Eskişehir Osmangazi & 1 & 0.8 & 0 & 0.0 & 1 & 0.7 \\
\hline Gazi & 8 & 7.0 & 1 & 3.3 & 9 & 6.3 \\
\hline Haliç & 1 & 0.8 & 0 & 0.0 & 1 & 0.7 \\
\hline İnönü & 0 & 0.0 & 1 & 3.3 & 1 & 0.7 \\
\hline İstanbul Bilgi & 1 & 0.8 & 0 & 0.0 & 1 & 0.7 \\
\hline İstanbul Teknik & 1 & 0.8 & 0 & 0.0 & 1 & 0.7 \\
\hline İstanbul & 7 & 6.1 & 1 & 3.3 & 8 & 5.5 \\
\hline $\begin{array}{l}\text { Kahramanmaraş Sütçü } \\
\text { İmam }\end{array}$ & 2 & 1.7 & 0 & 0.0 & 2 & 1.4 \\
\hline Karabük & 2 & 1.7 & 0 & 0.0 & 2 & 1.4 \\
\hline Karadeniz Teknik & 5 & 4.4 & 1 & 3.3 & 6 & 4.1 \\
\hline Kastamonu & 3 & 2.6 & 0 & 0.0 & 3 & 2.1 \\
\hline Kâtip Çelebi & 10 & 8.8 & 0 & 0.0 & 10 & 6.9 \\
\hline Kırklareli & 2 & 1.7 & 0 & 0.0 & 2 & 1.4 \\
\hline Mersin & 1 & 0.8 & 0 & 0.0 & 1 & 0.7 \\
\hline Muğla Sitk1 Koçman & 6 & 5.3 & 0 & 0.0 & 6 & 4.1 \\
\hline Namık Kemal & 6 & 5.3 & 1 & 3.3 & 7 & 4.9 \\
\hline Necmettin Erbakan & 3 & 2.6 & 0 & 0.0 & 3 & 2.1 \\
\hline Niğde & 3 & 2.6 & 0 & 0.0 & 3 & 2.1 \\
\hline ODTÜ & 2 & 1.7 & 0 & 0.0 & 2 & 1.4 \\
\hline Ondokuz Mayıs & 1 & 0.8 & 1 & 3.3 & 2 & 1.4 \\
\hline Sakarya & 0 & 0.8 & 2 & 6.7 & 2 & 1.4 \\
\hline Selçuk & 1 & 0.8 & 5 & 16,7 & 6 & 4.1 \\
\hline Süleyman Demirel & 1 & 0.8 & 1 & 3.3 & 2 & 1.4 \\
\hline Trakya & 3 & 2.6 & 0 & 0.0 & 3 & 2.1 \\
\hline Yaşar & 1 & 0.8 & 0 & 0.0 & 1 & 0.7 \\
\hline Yüzüncü Yıll & 1 & 0.8 & 0 & 0.0 & 1 & 0.7 \\
\hline Toplam & 114 & 100.0 & 30 & 100.0 & 144 & 100.0 \\
\hline
\end{tabular}

Tablo 4'te Kırsal Turizm kapsamında yer alan tezlerin üniversitelere göre dağılımı yer almaktadır. Çalışma kapsamına alınan tez çalışmaları genel olarak değerlendirildiğginde Kırsal Turizm ve kapsamında yer alan çalışmalarla ilgili en fazla $(\% 7,6)$ Ankara Üniversitesinde tez 
çalışması yapıldığı saptanırken bunu \%6.9 oranıyla Katip Çelebi, \%6.3 oranıyla Gazi, \%5.5 oranıyla İstanbul, \%4.9 oranıyla Çanakkale ve Namık Kemal, \%4.1 oranıyla Karadeniz Teknik, Muğla Sitkı Koçman ve Selçuk Üniversiteleri takip etmektedir.

Yüksek Lisans düzeyinde hazırlanan tezler en fazla (\%10.0) Katip Çelebi Üniversitesinde yapılırken bunu sırasıyla \% 7.0 oranıyla Gazi Üniversitesi, \%6.1 (eşit) oranıyla Çanakkale ve İstanbul Üniversiteleri, \%5.3 eşit oranıyla Dokuz Eylül, Muğla Sıtkı Koçman ve Namık Kemal Üniversiteleri, \%4.4 eşit oranıyla Ankara ve Karadeniz Teknik Üniversiteleri, \%3.5 oranıyla Atatürk Üniversitesi, \%2.6 eşit oranıyla Balıkesir, Düzce, Kastamonu, Necmettin Erbakan, Niğde ve Trakya Üniversiteleri, \% 1.7 eşit oranıyla Adnan Menderes, Afyon, Akdeniz, Kahramanmaraş Sütçü İmam, Karabük, Kırklareli ve Orta Doğu Teknik Üniversiteleri takip etmektedir. Çalıșma kapsamına alınan Doktora düzeyindeki tezler incelendiğinde ise Kırsal turizm ve kapsamında yer alan turizm türleri ile ilgili en fazla (\%20.0) Doktora tez çalışması Ankara Üniversitesinde gerçekleştirilmiştir. En fazla Doktora tezlerinin hazırlandığı üniversiteler ise sırasıyla Selçuk (\%16.7), Afyon Kocatepe (\%10.0), Balıkesir (\%6.7), Dokuz Eylül (\%6.7), Sakarya (\%6.7) üniversiteleridir.

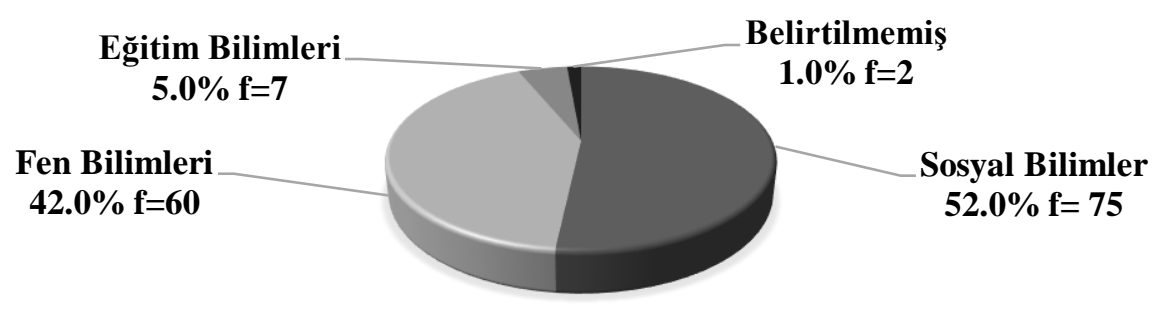

\section{Grafik 2: Kırsal Turizm Kapsamındaki Tezlerin Enstitülere Göre Dağılımı}

Kırsal turizm kapsamındaki tezlerin enstitülere göre dağılımı Grafik 2'de yer almaktadır. Buna göre Kırsal Turizm alanında hazırlanan tezler en fazla (\%52.0) Sosyal Bilimler Enstitüsünde harılanırken Fen Bilimleri Enstitüsünde hazırlanan tezlerin oranı da \%42.0'dır. Çalışma kapsamında değerlendirilen tezlerin \%1.0'inde çalışmanın hazırlandığı enstitü belirtilmezken tezlerin \%5.0'i de Eğitim Bilimleri Enstitüsünde hazırlanmıştır.

Tablo 5'te Kırsal Turizm ve kapsamında yer alan tezlerin anabilim dallarına göre dağılımı yer almaktadır. Tabloda yer alan değişkenlerin belirlenmesinde olabildiğince benzer kategoriler bir araya getirilmeye çalışılmıştır. 
Tablo 5: Kırsal Turizm Kapsamındaki Tezlerin Anabilim Dallarına Göre Dağılımı Anabilim Dalı

f $\%$

\begin{tabular}{lcc}
\hline Turizm/ Turizm İşletmeciliği/Turizm ve Otelcilik/Turizm Eğitimi & 47 & 32.7 \\
\hline Şehir ve Bölge Planlama & 8 & 5.6 \\
\hline İsletme & 7 & 4.9 \\
\hline Tarım Ekonomisi & 9 & 6.3 \\
\hline Sosyoloji & 2 & 1.4 \\
\hline Peyzaj/Peyzaj Mimarlı̆̆ı & 18 & 12.5 \\
\hline Avrupa Birliği & 1 & 0.7 \\
\hline Coğrafya & 12 & 8.3 \\
\hline Çevre Bilimleri/Kent Çevre Bilimleri & 2 & 1.4 \\
\hline Ekoturizm & 8 & 5.6 \\
\hline İ Mimarlık & 1 & 0.6 \\
\hline İktisat & 2 & 1.4 \\
\hline İlköğretim & 2 & 1.4 \\
\hline Kamu Yönetimi & 2 & 1.4 \\
\hline Orman Mühendisliği & 10 & 7.0 \\
\hline Ortaöğrenim Sosyal Bilimler & 3 & 2.1 \\
\hline Sürdürülebilir Tarım ve Tabii Kaynaklar & 1 & 0.6 \\
\hline Toprak Bilimi ve Bitki Besleme & 1 & 0.6 \\
\hline Türk Halk Bilimi & 2 & 1.4 \\
\hline Zootekni & 1 & 0.6 \\
\hline Belirtilmemiş & 5 & 3.5 \\
\hline TOPLAM & $\mathbf{1 4 4}$ & $\mathbf{1 0 0 . 0}$ \\
\hline
\end{tabular}

Tablo 5 değerlendirildiğinde Kırsal Turizm ve kapsamında yer alan tezlerin en fazla oranla yer aldığı Anabilim Dalı Turizm kategorisinde yer alan 'Turizm/ Turizm İşletmeciliği/Turizm ve Otelcilik/Turizm Eğitimi Ana Bilim Dalıdır (\%32.7). Bunu sırasıyla Peyzaj/Peyzaj Mimarlığı (\%12.5), Coğrafya (\%8.3), Orman Mühendisliği (\%7.0), Tarım Ekonomisi (\%6.3), eşit oranlarla (\%5.6) Șehir ve Bölge Planlama, Ekoturizm, \%4.9 oranıla İșletme, \%2.1 oranılyla Ortaöğrenim Sosyal Bilimler, eşit oranlarla (\%1.4) Sosyoloji, İktisat, İlköğretim ve Kamu Yönetimi takip etmektedir. Çalışma kapsamında değerlendirilen 144 tezin \%3.5'inde ise Ana Bilim Dalı belirtilmemiştir.

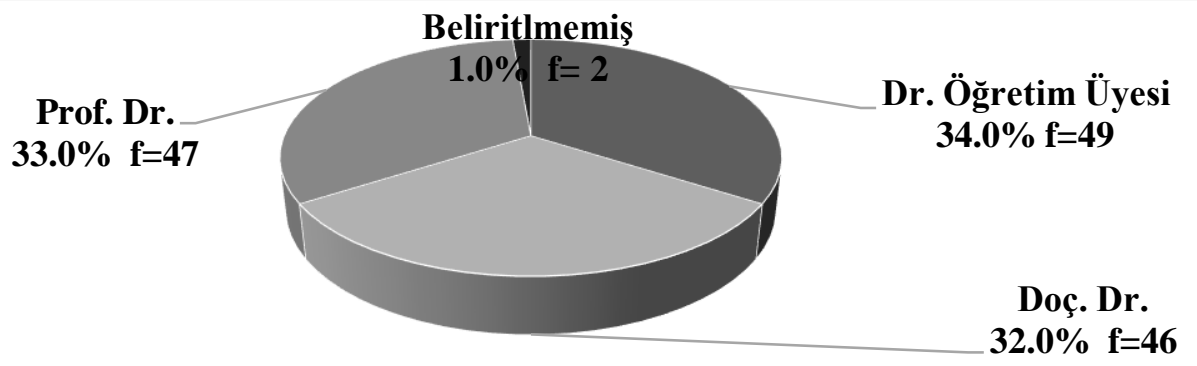

- Dr. Öğretim Üyesi " Doç. Dr. " Prof. Dr. - Beliritlmemiş

Grafik 3: Kırsal Turizm Kapsamındaki Tezleri Yürüten Danışmanların Unvanları

Kırsal Turizm Kapsamındaki Tezleri Yürüten Danışmanların Unvanlarına göre dağılımı Grafik 3'te yer almaktadır. Buna göre Kırsal Turizm ve kapsamında yer alan turizm türlerine ilişskin yapılan Yüksek Lisans ve Doktora tezlerine danışmanlık yapan öğretim üyeleri yüzdelik dilim 
açısından birbirlerine benzerdir. Buna göre lisansüstü tez çalışmalarına danışmanlık yapan öğretim üyeleri sırasıyla Dr. Öğretim Üyesi (\%34.0), Prof. Dr. (\%33.0) ve Doç. Dr. (\%32.0)'dur. Diğer taraftan çalışma kapsamında değerlendirilen tezlerden \%1.0'i de tez danışmanı öğretim üyesi ve unvanını belirtmemiştir.

Tablo 6: Kırsal Turizm Kapsamında Yer Alan Tezlerin Sayfa Sayıları

\begin{tabular}{lcccccc}
\hline SAYFA & \multicolumn{2}{c}{ YL } & \multicolumn{2}{c}{ DR } & \multicolumn{2}{c}{ TOPLAM } \\
\cline { 2 - 7 } SAYISI & f & \% & f & \% & f & \% \\
\hline 100 ve alt1 & 36 & 31.6 & 0 & 0.0 & 36 & 25.0 \\
\hline $101-200$ & 65 & 57.0 & 9 & 30.0 & 74 & 51.4 \\
\hline $201-300$ & 12 & 10.5 & 19 & 63.4 & 31 & 21.5 \\
\hline $301-400$ & 1 & 0.9 & 1 & 3.3 & 2 & 1.4 \\
\hline 401 ve üzeri & 0 & 0.0 & 1 & 3,3 & 1 & 0.7 \\
\hline Toplam & $\mathbf{1 1 4}$ & $\mathbf{1 0 0 . 0}$ & $\mathbf{3 0}$ & $\mathbf{1 0 0 . 0}$ & $\mathbf{1 4 4}$ & $\mathbf{1 0 0}$ \\
\hline
\end{tabular}

Kırsal Turizm kapsamında yer alan tezlerin sayfa sayıları Tablo 6'da yer almaktadır. Genel olarak Yüksek Lisans ve Doktora tezleri toplam olarak değerlendirildiğinde söz konusu tezlerin yarısından fazlası (\%51.4) 101-200 sayfadır. Bunu sirasiyla 201-300 sayfa olan tezler (\%21.5), 100 sayfa ve daha az olan tezler (\%25.0), 301-400 sayfa olan tezler ve 401 sayfa ve üzeri sayfa olan tezler (\%0.7) takip etmektedir. Kırsal turizm kapsamında yer alan tezler düzeyleri açısından değerlendirildiğinde Yüksek Lisans düzeyindeki tezlerin \%57.0'si 101-200 sayfa arasındayken Doktora düzeyindeki tezlerin \%63.4'ü 2001-300 sayfa arasındadır.

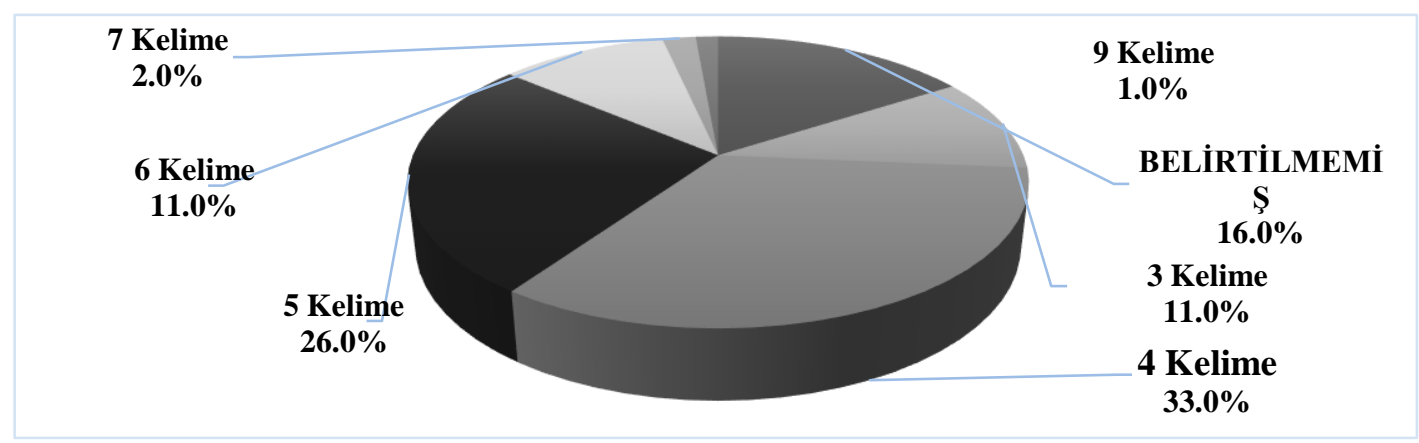

Grafik 4: Kırsal Turizm Kapsamındaki Tezlerin Anahtar Kelime Sayısına Göre Dağılımı

Çalışma kapsamında tez çalışmalarında yer alan özet kısımlarında kullanılan anahtar kelime sayıları incelenmiş ve Grafik 4'te değerlendirilmiştir. Buna göre; araştırma kapsamında değerlendirilen çalışmaların \%33.0'ünde 4 anahtra kelime, \%26.0'sında 5 anahtar kelime, $\% 11.0$ 'inde 6 anahtar kelime, yine \%11.0'inde 3 anahtar kelime, \%2.0'sinde 7 anhtar kelime ve $\% 1.0$ 'inde 9 anahtar kelime kullanılmıştır. Ayrıca çalışma kapsamında değerlendirilen tezlerin \%16.0'sında anahtar kelimenin olmadığı belirlenmiştir. 
Tablo 7: Kırsal Turizm ve Türlerinin Yöntem İçeriğine Göre Dağılımı

\begin{tabular}{|c|c|c|c|c|c|c|c|}
\hline \multirow{2}{*}{ İÇERİK } & \multicolumn{3}{|c|}{ Yüksek Lisans } & \multicolumn{2}{|c|}{ Doktora } & \multicolumn{2}{|c|}{ TOPLAM } \\
\hline & Kategori & $\mathbf{f}$ & $\%$ & f & $\%$ & $\mathbf{f}$ & $\%$ \\
\hline \multirow{2}{*}{$\begin{array}{l}\text { Yöntemin } \\
\text { Varlığ }\end{array}$} & Evet & 91 & 79.1 & 27 & 90.0 & 118 & 81.9 \\
\hline & Hayır & 23 & 20.9 & 3 & 10.0 & 26 & 18.1 \\
\hline \multirow{4}{*}{$\begin{array}{l}\text { Kullanılan } \\
\text { Yöntem }\end{array}$} & Nicel & 48 & 42.2 & 10 & 33.3 & 58 & 40.3 \\
\hline & Nitel & 43 & 37.7 & 12 & 40.0 & 55 & 38.2 \\
\hline & Karma & 12 & 10.5 & 6 & 20.0 & 18 & 12.5 \\
\hline & Belirtilmemiş & 11 & 9.6 & 2 & 6.7 & 13 & 9.0 \\
\hline \multirow{6}{*}{$\begin{array}{l}\text { Veri Toplama } \\
\text { Tekniği }\end{array}$} & Anket & 45 & 39.5 & 10 & 33.3 & 55 & 38.1 \\
\hline & Mülakat & 18 & 15.8 & 8 & 26.7 & 26 & 18.1 \\
\hline & Literatür Tarama & 19 & 16.7 & 4 & 13.3 & 23 & 16.0 \\
\hline & Gözlem & 7 & 6.1 & 2 & 6.7 & 9 & 6.3 \\
\hline & Karma & 16 & 14.0 & 5 & 16.7 & 21 & 14.6 \\
\hline & Belirtilmemiş & 9 & 7.9 & 1 & 3.3 & 10 & 6.9 \\
\hline \multirow{2}{*}{ Evren Tarifi } & Var & 70 & 61.4 & 24 & 80.0 & 94 & 65.3 \\
\hline & Yok & 44 & 38.6 & 6 & 20.0 & 50 & 34.7 \\
\hline \multirow{6}{*}{$\begin{array}{l}\text { Örneklem } \\
\text { Büyü̈klüğüu }\end{array}$} & $0-100$ & 32 & 28.1 & 10 & 33.3 & 42 & 29.2 \\
\hline & $101-200$ & 18 & 15.8 & 3 & 10.0 & 21 & 14.6 \\
\hline & $201-300$ & 3 & 2.6 & 2 & 6.7 & 5 & 3.5 \\
\hline & $301-400$ & 10 & 8.8 & 5 & 16.6 & 15 & 10.3 \\
\hline & 400 ve daha fazla & 1 & 0.9 & 2 & 6.7 & 3 & 2.1 \\
\hline & Belirtilmemiş & 50 & 43.8 & 8 & 26.7 & 58 & 40.3 \\
\hline \multirow{4}{*}{$\begin{array}{l}\text { Örnekleme } \\
\text { Seçim Yöntemi }\end{array}$} & Basit Rastgele & 14 & 12.3 & 10 & 33.4 & 24 & 16.7 \\
\hline & Kasti & 13 & 11.4 & 4 & 13.3 & 17 & 11.8 \\
\hline & Kolayda & 10 & 8.8 & 4 & 13.3 & 14 & 9.7 \\
\hline & Belirtilmemiş & 77 & 67.5 & 12 & 40.0 & 89 & 61.8 \\
\hline
\end{tabular}

Kırsal Turizm ve Türlerine İlişkin Alan Araştırması İçeren Tezlerde Yöntem İçeriğine Göre Dağılımı Tablo 7'de yer almaktadır. Buna göre çalışma kapsamına alınan 144 tezin \%81.9'unda yöntem kısmına yer verilirken \%18.1'inde yöntem kısmına yer verilmediği görülmüştür. Çalışmalar düzeylerine göre değerlendirildiğinde ise Yüksek Lisans tezlerinin \%20.9'unda ve Doktora tezlerinin \%18.1'inde yöntem kısmı bulunmadığı saptanmıştır. Çalışma kapsamına alınan tezlerde kullanılan yöntem değerlendirildiğinde 144 tezin \%9.0'unda (13 adet) çalışmada kullanılan yöntemin belirtilmediği, tezlerin \%40.3'ünde nicel, \%38.2'sinde nitel ve \%12.5'inde karma (nitel ve nicel) kullanıldığı saptanmıştır. Tezlerde kullanılan yöntem çalışmaların düzeyi açısından değerlendirildiğinde Yüksek Lisans tezlerinde en fazla (\%42.2) nicel yöntemlerin kullanıldığı ve bunu nitel (\%37.7) ve karma (\%10.5) yöntemlerin takip ettiği saptanmıştır. Doktoro tezlerinde ise en fazla (\%40.0) nitel yöntemler kullanılırken bunu nicel (\%33.3) ve karma yöntemler takip etmiştir. Yüksek Lisans tezlerinin \%9.6'sinda ve Doktora tezlerinin \%6.7'sinde yöntem bulunmamaktadır.

Çalışma kapsamına alınan lisansüstü tezlerin \%38.1'inde veri toplama tekniği olarak anket kullanılırken \%18.1'inde Mülakat, \%16.0'sında Literatür taraması, \%14.6'sinda Karma veri toplama yöntemi kullanılırken çalışmaların \%6,9'unda ise veri toplama tekniğine yer verilmemiştir. Yüksek Lisans tezlerinde en fazla (\%39.5) kullanılan veri toplama tekniği anket iken bunu sırasılyla Literatür Taraması (\%16.7), Mülakat (\%15.8) ve Karma (\%14.0) veri toplama tekniği takip etmektedir. Doktora tezlerinde ise en fazla (\%33.3) kullanılan veri toplama tekniği anket iken bunu sirasıyla Mülakat (\%26.7), Karma yöntem (\%16.7) ve Literatür Taraması (\%13.3) takip etmektedir. Yüksek Lisans tezlerini \% 7.9'unda, Doktora tezlerinin ise \%3.3'ünde veri toplama tekniği belirtilmemiştir. 
Çalışma kapsamında değerlendirilen tezlerin \%65.3'ünde evren tarifi yer alırken \%34.7'sinde evren tarifi bulunmamaktadır. Tezlerde evren tarifinin bulunma durumu çalışmaların düzeylerine göre değerlendirildiğinde Yüksek Lisans tezlerinin \%38.6'sında, Doktora tezlerinin ise \%20.0'sinde evren tarifi yer almamaktadır. Çalışma kapsamına alınan tezler örneklem büyüklüğü açısından değerlendirildiğinde çalışmaların \%40.3'ünde örneklem büyüklüğünün hesaplanmadığı (belirtilmediği) görülmüştür. Yüksek Lisans tezlerinin \%43.8'inde, Doktora tezlerinin ise $\% 26.7$ 'sinde örneklem büyüklüğü belirtilmemiştir. Diğer taraftan Yüksek Lisans tezlerinin \%28.1'i, Doktora tezlerinin \%33.3'ü 0-100 sayfa sayısına sahiptir.

Çalışmaya konu olan tez çalışmalarının önemli bir kısmında (\%61.8) örnekleme seçim yöntemine yer verilmediği görülmektedir. Yüksek Lisans tezlerinin yarıdan fazlasında (\%67.5) Örnekleme Seçim Yöntemine yer verilmezken söz konusu çalışmaların \%12.3'ünde Basit Rastgele, \%11.4'ünde kasti ve \%8.8'inde kolayda örnekleme seçim yönteminin kullanıldığı belirlenmiştir. Konu Doktora tezleri açısından değerlendirildiğinde Doktora tezlerinin \%40.0'ında örnekleme seçim yönteminin belirtilmediği, \%33.4'ünde Basit Rastgele, \%13.3'ünde (eşit oranlarla) ise kasti ve kolayda örnekleme seçim yöntemlerinin kullanıldığı saptanmıştır.

\section{Sonuç ve Öneriler}

Kırsal turizm günümüzde sadece gelişmekte olan ülkelerin değil aynı zamanda sosyoekonomik açıdan gelişmiş olan pek çok ülkenin de üzerinde durdukları en önemli konulardan biridir. Gelişmiş ülkelerde yaşayan insanlar doğala dönme çabasıyla kırsal turizmi tercih ederken gelişmekte olan ülkeler de yaşayan insanlar ise kırsal turizm potansiyellerini kullanarak turizm endüstrisinden pay alma çabası içerisindedir. Konu ülkemiz açısından değerlendirildiğinde Türkiye sahip olduğu kırsal alan değerleriyle turistik bir ürün çeşidi olarak son derece önemli kaynaklara sahiptir. Özellikle ülkemizin coğrafi konumu göz önünde bulundurulduğunda kırsal turizm kapsamında değerlendirilebilecek pek çok turizm türünden bahsedilebilmektedir. Turistleri kırsal turizme yönelten motivasyonlar kırsal alanları deneyimlemek olduğundan kırsal turizm kapsamına yayla turizmi, agro turizm, botanik turizmi, mağara turizmi gibi pek çok farklı turizm türü de girmektedir. Dolayısıyla kırsal turizm kapsamında değerlendirilen turizm türlerine ilişkin alan yazında pek çok çalışma olduğu hatta kırsal turizm ana temasıyla kongre ve sempozyumların da yapıldığı görülmektedir. Turizm talebinin artmasına önemli katkı sağlayan kırsal turizm ve türleri ile ilgili yapılan ve yapılacak çalışmaların hem turizmin gelişimi ve sürdürülebilirliğine hem de alan yazına olumlu etkiler sağlayacağı düşünülmektedir.

Bulgular değerlendirildiğinde ise, kırsal turizm kapsamında çalışılan yüksek lisans ve doktora tezlerinin büyük çoğunluğunun eko turizm alanında olması dikkat çekicidir. Özellikle Türkiye'nin zengin doğal dokusu düşünüldügünde, kırsal rekreasyon ve çiftlik konularında hiç yüksek lisans tezinin olmaması, doktora tezlerinde ise av turizmi, da turizmi, botanik ve kuş gözlemciliği konularında çalışmaların olmaması bir eksiklik olarak değerlendirilmektedir. Türkiye'de sadece 30 adet doktora tezinin kırsal turizm çerçevesinde olması da dikkat çekici sonuçlardan biridir. Dolayısıyla turizm açısından bölgesel kalkınmaya ve ülkemizde gerçekleştirilebilecek kırsal turizm türlerini geliştirmeyi teşvik edecek çalışmalara ağırlık verilmesi, bu konuda lisansüstü öğrenim gören öğrencilerin teşvik edilmesi önerilmektedir. Araştırma için seçilecek bölgelerdeki topluma, doğal yaşama, ekonomiye bir kalkınma planı sunması açısından yapılabilecek her çalışma büyük önem taşımaktadır. Ancak çalışma sonucunda elde edilen verilere göre tezler çoğunlukla büyük şehirlerdeki üniversitelerde yazılmıştır. Kırsal turizme ilişkin önemli kaynak oluşturan küçük şehirlerin turizmden gelir elde etmelerinde bu bölgelerin kırsal turizm potansiyellerini ortaya koymanın önemli olduğu düşünülmektedir. Bu nedenle özellikle kırsal turizm ve türlerine ilişkin potansiyele sahip olan küçük şehirlerde yapılacak çalışmaların bu bölgelerin hem kırsal kalkınmaya katkı sağlayacağı hem de turizmden gelir elde etmelerine yarar sağlayacağı ön görülmektedir. 
Çalışma kapsamında değerlendirilen lisansüstü tez çalışmalarının büyük çoğunluğunun 2010 yılı ve sonrasında gerçekleştirildiği belirlenmiştir. $\mathrm{Bu}$ durum turistik ürün çeşitlendirmesinin ülkemizde 2000'li yıllardan sonra incelenmeye başlanması ve son yıllarda sürdürülebilir turizm kapsamında alternatif turizm türlerine verilen önemin artmasıyla açıklanabilir. Araştırma kapsamında elde edilen önemli bulgulardan biri de hazırlanan tez çalışmalarının en fazla (\%52.0) Sosyal Bilimler Enstitüsü'nde yayınlanmasına rağmen Fen Bilimleri Enstitüsünde yayınlanan çalışmaların oranın da oldukça yüksek olmasıdır (\%42.0). Diğer taraftan söz konusu çalışmalar en fazla Turizm İşletmeciliği Anabilim Dalı'nda gerçekleştirilirken bunu Peyzaj Mimarlığı, Coğrafya ve Orman Mühendisliği takip etmektedir. Turizmin interdisipliner yapısı göz önünde bulundurulduğunda kırsal turizm ve türlerinin farklı1 anabilim dallarında çalışı1mış olması bu turizm türlerinin tanıtım ve gelişim faaliyetleri açısından umut vadedicidir. Bundan sonra yapılacak lisansüstü çalışmalarda da kırsal turizm ve türlerinin interdisipliner olarak ele alınması talep açısından önemli potansiyele sahip olan kırsal turizm ve türlerinin gelişimine katkı sağlayacaktır. Çalışmalara danışmanlık yapan öğretim üyeleri açısından önemli bir fark görülmemiştir. Ayrıca çalışma kapsamına alınan tezlerin neredeyse tamamının Türkçe hazırlandığı sadece 3 Yüksek Lisans tezinin İngilizce olarak hazırlandığı belirlenmiştir. Günümüzde özellikle dil eğitimine daha fazla önem veriliyor olması ülkemizin uluslararasılaşmasında oldukça önemli yere sahiptir. Özellikle Türkçe dışındaki dillerde yapılan çalışmalar da hem Türkiye'nin kırsal turizm ve türlerine ilişkin potansiyelinin öğrenilmesine hem de Türkiye turizm literatürünün uluslararası tanınmasına da neden olacaktır. Dolayısıyla yapılan lisansüstü çalışmalarda uluslararası dilin daha etkin kullanılması önerilmektedir.

Araştırma kapsamında kırsal turizm ve türlerinin yöntem içeriğine incelenmiştir. Buna göre Yüksek Lisans tezlerinin \%20.9'unda, Doktora tezlerinin ise \%10'unda Yöntem bölümünün yer almadığ 1 bulunmuştur. Yüksek Lisans tezlerinin üçte birinden fazlasında Doktora tezlerinin ise \%10.0'unda evren tarifi bulunmazken Yüksek Lisans tezlerinin yarı yakınında örneklem büyüklüğü belirtilmemiş, Doktora tezlerinde ise en fazla 0-100 kişi arasındaki örneklem büyüklügü kullanılmıştır. Yüksek Lisans tezlerinin oldukça önemli bir bölümünde örneklem seçim yöntemine yer verilmezken Doktora tezlerinde en fazla Basit Rastgele Örnekleme yöntemi kullanılmıştır. Akademik çalışmalarda yöntem bölümünün çalışmanın neden, nasıl ve hangi amaçla yapıldığını ifade eden kısım olduğu göz önünde bulundurulduğunda lisansüstü düzeyde yapılan çalışmaların bir kısmında bu bölümün yer almaması dikkat çekicidir. Dolayısıyla konu ile ilgili lisansüstü araştırmalardan elde edilen bulgu ve sonuçların genellenebilmesi hususunda bazı belirsizliklerin olduğu söylenebilir.

Çalışma kapsamında değerlendirilen Yüksek Lisans Tezlerinde en fazla nicel araştırma yöntemi kullanılırken Doktora tezlerinde ise en fazla nitel araştırma yöntemi kullanılmıştır. Hem Yüksek Lisans hem de Doktora tezlerinde Veri Toplama Tekniği olarak en fazla anket yönteminin kullanıldığı belirlenmiştir. Bilgisayar destekli istatistik programlarının gelişmesi ve anketlerden elde edilen verilerin bu programlara girilerek analiz edilmesinin nispeten daha kolay olması tez çalışmalarında anketin veri toplama aracı olarak kullanılmasının nedenlerinden biri olarak değerlendirilebilir. Artan lisan üstü çalışmalar, ilgili literatürlerin gelişim göstermesini sağlamakta, sonraki araştırmacılara yararlanabilecekleri kaynakça oluşturmaktadır. Dolayısıyla Kırsal turizm ve kapsamında yer alan turizm türlerine ilişkin artış literatüre ve araştırmacılara önemli katk1 sağlamaktadır. Ancak çalışma sonucunda elde edilen verilerden hareketle bundan sonra yapılacak olan lisan üstü tezlerde bilimsel niteliğe daha fazla önem verilmesi gerektiği ortaya çıkmıştır.

\section{Kaynakça}

Albayrak, A. (2013). Alternatif Turizm. Ankara: Detay Yayınc1l1k. 
Ayaz, N. ve Türkmen, B. M. (2018). Yöresel Yiyecekleri Konu Alan Lisansüstü Tezlerin Bibliyometrik Analizi. Gastroia: Journal of Gastronomy And Travel Research, 2(1): 22-38.

Bozok, D., K1lı̧, S. N., Özdemir, S. S. (2017). Turizm Literatüründe Kırsal Turizmin Bibliyometrik Analizi. Journal of Human Sciences, 14(1): 187-202. doi:10.14687/jhs.v14i1.4274.

Cevizkaya, G., Selin, İ. ve Avcıkurt, C. (2014). Turizm Alan Yazınında Engelliler İle İlgili Çalışmaların Bibliyometrik Pofili (2000-2013), Gazi Üniversitesi Turizm Fakültesi, 15. Ulusal Turizm Kongresi, 13-16 Kasım 2014, Ankara, 145-151.

Çeken, H., Karadağ, L. ve Dalgın, T. (2007). Kırsal Kalkınmada Yeni Bir Yaklaşım Kırsal Turizm ve Türkiye'ye Yönelik Teorik Bir Çalışma, Artvin Çoruh Üniversitesi Orman Fakültesi Dergisi, 8(1) : 1-14.

Gökkaya, S., Acar, A. ve Yıldırım, M. (2017). Karabük Üniversitesi Sosyal Bilimler Enstitüsü Dergisi, Özel Sayı 3: 122-130.

Güçlü, H. N. (2014). Türkiye'de Lisansüstü Turizm Tezlerinin Bibliyometrik Profili (1990-2013). VII. Lisansüstü Turizm Öğrencileri Araştırma Kongresi: 212-221, 04-05 Nisan 2014, Kuşadası, Aydın. ISBN: 978-605-4940-00-4.

Kervankıran, İ. ve Şardağ, A. (2018). Türkiye'de Turizm Coğrafyası Araştırmaları: Lisansüstü Tezlere Yönelik Bir İçerik Analizi, International Journal of Geography and Geography Education, 39: 151-170.

Özçatalbaş, O. (2006). Türkiye'de Kırsal Turizm Faaliyetleri ve Geliştirme Olanakları, TMMOB Turizm ve Mimarlık Sempozyumu Bildiri Kitabı, Antalya.

Sünnetçioğlu, A., Yalçınkaya, P., Olcay, M., ve Okan, Ş. (2017). Turizm Alanında Yazılmış Olan Gastronomiye İlişkin Tezlerin Bibliyometrik Profili, Journal of Tourism and Gastronomy Studies, 5(Special Issue 2): 345-354.

Şahin, S. ve Acun, A. (2015). Turist Rehberliği Alanının Bibliyometrik Profili (Ulusal Turizm Kongreleri Bildirileri). Ballkesir University The Journal of Social Sciences Institute, Volume: 18(34): 213-235.

Şerefoğlu, C. (2009). Kalkınmada Kırsal Turizmin Rolü- 2007- 2013 Yılları Arasında Ülkemizde Uygulanacak Olan Ipard Kırsal Kalkınma Programındaki Yeri, Önemi ve Beklenen Gelişmeler, Uzmanlık Tezi, T.C. Tarım ve Köyişleri Bakanlığı, Ankara.

T.C. Kültür ve Turizm Bakanlığı. Turizm Çeşitleri. http://www.kultur.gov.tr/TR-96269/turizmcesitleri.html (Erişim: 16.12.2019).

Tayfun, A., Ülker, M., Gökçe, Y.,Tengilimoğlu, E., Sürücü, Ç. ve Durmaz, M. (2018). Turizm Alanında Yiyecek ve İçecek ile İlgili Lisansüstü Tezlerin Bibliyometrik Analiz, Journal of Tourism ve Gastronomy Studies, 6(2): 523-547. DOI: 10.21325/jotags.2018.227.

Uçar, M., Uçar, H., Kurnaz, A. ve Kurnaz H.A. (2012). Kırsal Turizmin Sosyo-Ekonomik Yapıya Etkisi ve Fethiye Örneği, KMÜ Sosyal ve Ekonomik Araştırmalar Dergisi, 14 (22): 75-82.

UNWTO. Rural and Mountain Tourism. http://marketintelligence.unwto.org/content/rural-andmountain-tourism (Erişim: 16.05.2019).

Yazıc1, K., Aslan, B.G. ve Ankaya, F. (2017). Potential of Rural Tourism and Ecotourism and SWOT Analysis: Case of Başkale (Van, Turkey) and Its Surroundings, Karabük Üniversitesi Sosyal Bilimler Enstitüsü Dergisi, 3: 132-145. 